\title{
Optimal slope angle selection of an evacuated tube collector for domestic solar water heating
}

\author{
Rigardt Alfred Maarten Coetzee ${ }^{1 *}$, Aggrey Mwesigye ${ }^{2}$ Zhongjie Huan $^{1}$ \\ ${ }^{1}$ Department of Mechanical Engineering, Mechatronics and Industrial Design, Tshwane University of Technology, \\ Private Bag X860, Pretoria 0001, South Africa \\ ${ }^{2}$ School of Mechanical, Industrial and Aeronautical Engineering, University of the Witwatersrand, Private Bag 3, \\ Johannesburg 2050, South Africa
}

\begin{abstract}
A pressurised system utilising evacuated tube collectors with internal heat pipes was investigated for the production of hot service-water for domestic use during all seasons in Pretoria, South Africa. The investigation focused on the prediction of seasonal hourly performance trends and the maximum thermal performance at the optimal slope angle. This study was accomplished by developing the system's theoretical performance model which was solved numerically using Engineering Equation Solver. Results show the thermal performance of the system during the sequential seasons at different slope angles. Optimal performance parameters that influence the collector overall performance, depending on the water consumption of the occupants, were obtained and presented. In summer, a $25^{\circ}$ slope angle produced the highest useful heat rate and in winter, a slope angle of $40^{\circ}$ produced the highest.
\end{abstract}

Lastly, a 20-tube collector system operated maximally in September, reaching an outlet temperature of $103.98{ }^{\circ} \mathrm{C}$ and yielding a useful heat rate of $1919.85 \mathrm{~W}$.

Keywords: solar thermal, simple system model, dual tank system, heat pipes, slope angle.

\footnotetext{
* Corresponding author: Tel: +27 (0) 765008904

Email:210114220@tut4life.ac.za

coetzeerigardt@yahoo.com
} 


\section{Nomenclature}

\section{Symbols}

\begin{tabular}{clcl}
$\mathrm{h}_{\mathrm{fg}}$ & Latent heat of vaporisation $[\mathrm{kJ} / \mathrm{kg}]$ & $\mathrm{R}$ & Thermal resistance $[\mathrm{K} / \mathrm{W}]$ \\
$\mathrm{Q}, \mathrm{Q}$ & Heat transfer rate $[\mathrm{W}]$ & $\mathrm{Re}$ & Reynolds number $[-]$ \\
$\Delta \mathrm{x}$ & Thickness $[\mathrm{mm}]$ & $\mathrm{S}$ & Absorbed irradiance $[\mathrm{W}]$ \\
$\mathrm{A}$ & Area $\left[\mathrm{m}^{2}\right]$ & $\mathrm{T}$ & Temperature $\left[{ }^{\circ} \mathrm{C}\right]$ \\
$\mathrm{Cp}$ & Specific heat $[\mathrm{kJ} / \mathrm{kg} \mathrm{K}]$ & $\mathrm{t}$ & Time $[\mathrm{Sec}]$ \\
$\mathrm{D}$ & Diameter $[\mathrm{m}]$ & $\mathrm{UA}$ & Overall heat transfer coefficient $[\mathrm{W} / \mathrm{K}]$ \\
$\mathrm{h}$ & Heat transfer coefficient $\left[\mathrm{W} / \mathrm{m}^{2} \mathrm{~K}\right]$ & $\mathrm{V}$ & Velocity $[\mathrm{m} / \mathrm{s}]$ \\
$\mathrm{L}$ & Length $[\mathrm{m}]$ & $\mathrm{DEM}$ & Demand $[\mathrm{W}]$ \\
$\mathrm{M}$ & Mass $[\mathrm{kg}]$ & $\dot{m}$ & Mass flow rate $[\mathrm{kg} / \mathrm{s}]$ \\
$\mathrm{Nu}$ & Nusselt number $[-]$ & & \\
\hline & & &
\end{tabular}

\section{Greek symbols}

$\mathrm{u}$ Dynamic viscosity $[\mathrm{kg} / \mathrm{m} \mathrm{s}]$

$\mathrm{v} \quad$ Kinematic viscosity $\left[\mathrm{m}^{2} / \mathrm{s}\right]$

$\alpha \quad$ Absorptance[-]

$\varepsilon \quad$ Emissivity[-]

$\eta \quad$ Efficiency [\%]

$\rho \quad$ Density $\left[\mathrm{kg} / \mathrm{m}^{3}\right]$

\section{Subscripts}

\begin{tabular}{clcl} 
a & Ambient & $\mathrm{mu}$ & Public main \\
comb & Combined & $\mathrm{n}$ & $\mathrm{New}$ \\
cond & Condenser & $\mathrm{o}$ & Outlet \\
$\mathrm{DW}$ & Dewar tube & $\mathrm{OT}$ & Outer tube \\
env & Environment & $\mathrm{r}$ & Receiver \\
evap & Evaporator & $\mathrm{rad}$ & Radiation \\
$\mathrm{f}$ & Fluid & $\mathrm{s}$ & Storage \\
$\mathrm{g}$ & Glass & sat & Saturation \\
$\mathrm{hp}$ & Heat pipe & $\mathrm{st}$ & Storage tank \\
INS & Insolation & $\mathrm{tl}$ & Tank loss \\
$\mathrm{IT}$ & Inner tube & $\mathrm{u}$ & Useful \\
$\mathrm{k}$ & Conductivity & $\mathrm{v}$ & Vapour \\
$\mathrm{l}$ & Liquid & $\mathrm{w}$ & Wall of absorption \\
man & Manifold & & \\
\hline
\end{tabular}




\section{Introduction}

The continuing development of South Africa's infrastructure, domestic housing and increasing need for high-quality living conditions is causing a continual rise in the country's energy demand. Energy providers are struggling to supply this rising demand and therefore turn to nonconventional sources to assist in this need. The interest in the use of renewable energy resources such as solar, wind, geothermal and others is further accelerated by the uncertainty of oil and fuel prices, the need to ensure energy security and the increasing concerns of climate change [1]. Intrinsically, the South African solar thermal market is growing due to the interest growth in utilising this solar thermal technology for domestic water heating in residential areas. However, most South African households are not yet fully convinced of the functionality of these solar thermal products. This may be due to lack of understanding, poor quality of the installations and components, and functionality this field currently offers in the residential market [2]. High and low-pressure solar water-heating $(\mathrm{SWH})$ units are the most favoured and commonly installed systems in upper- and middleincome homes [3]. Moreover, studies have shown that domestic energy demand can decrease by 30 $50 \%$ when SWH units are implemented [3].

Several studies have examined parameters affecting the performance and feasibility of SWH systems. One such is by Allouhi et al. [4] in which two types of forced fluid circulated solar collectors, a flat plate collector (FPC) and an evacuated tube collector (ETC) were analysed in six regions of Morocco. A consumption profile of a typical family house was used to conduct a theoretical analysis. It was shown that these systems not only have significant potential, especially the ETC systems, but also that climate and location significantly influence the overall system performance. The research team of Hazami et al. [5] investigated a $265 \mathrm{~L} /$ day SWH for a typical family home in Tunisia. The long-term performance of the system utilising either an FPC or an ETC with internal heat pipe configuration was tested experimentally and validated by means of simulation software (TRNSYS). It was found that the ETC presents many advantages over its FPC counterpart's thermal performance. Therefore, the ETC SWH is more appropriate and allows integration with more advanced systems, such as systems having heat pumps and absorption chillers that require a higher temperature. Mazarron et al. [6] studied the effect of the required tank water temperature (rTWT) on the energy performance of an SWH system utilising a 24tube ETC pressurised with an $80 \mathrm{~L}$ tank, in Madrid, Spain. Experimentally analysed results showed that the rTWT has a clear influence on the ETC, tank, and the global system efficiency.
A number of other studies were conducted to investigate the effect of various parameters on the overall performance of an evacuated tube with heat pipe collectors (ETHPC). Jafarkazemi and Abdi [7] compared a theoretical model with experimental tests of a 4- and 19-tube ETHPC. The theoretical model was based on linear heat transfer formulas and the experimental tests were performed using the ISO 9806-1 test procedure [8]. It was established that the theoretical model was in good agreement with the results of the experimental tests. Using a method similar to the previous study, Jafarkazemi et al. [9] investigated the efficiency of an ETHPC by means of exergy analysis and the second law of thermodynamics. It was demonstrated that the difference between the water inlet temperature and the ambient temperature led to a decrease in energy efficiency but an increase in the exergy efficiency. Hlaing and Soe [10] investigated the heat transfer performance of a 30-tube ETHPC. The study modelled the heat transfer between the inner and outer glass tube along with the heat transfer through the heat pipe wall using COMSOL Multiphysics. One of the conclusions was that the surface heat fluxes between the internal parts are not much different and suitable to obtain the required heat conduction within the parts. The number of absorbing collectors is of utmost important for various applications, since the hot water outlet temperature depends on the number of tubes, the amount of solar radiation and environmental conditions [10]. Azad [11] designed and constructed an ETHPC where its performance was measured using an outdoor test facility. A theoretical model based on the effectiveness-number of transfer units method was developed to evaluate the thermal efficiency of the collector, inlet, and outlet temperatures. The model predictions compared favourably with previous literature.

Research on the performance of solar collectors in South Africa is not widespread. Briel and Bunt [12] determined the optimum angle of inclination, in terms of energy input, of two fixed-flat plate solar collectors in Johannesburg. The study established an optimum mounting angle of $30^{\circ}$. An experimental investigation to obtain the maximum power output of photovoltaic panels during the winter seasons in the Vaal Triangle (Emfuleni) was undertaken by Asowata et al. [13]. They compared the results with a mathematical and a parametric model and determined that the optimum power output of these panels was between $26^{\circ}$ and $36^{\circ}$. Hayek et al. [14] experimentally investigated the overall performance of a water-in-glass ETC and a heat pipe ETC. The experimental tests were done at tilts of $30^{\circ}, 45^{\circ}$ and $55^{\circ}$ and the conclusion was that the tilt angle is a non-negligible parameter, especially at low irradiance values. 
The performance of any solar water-heating system, as noted in most of the studies discussed above, depends on the season of the year, the weather conditions in which it is operating, the type of collectors used and the angle at which they are oriented. Moreover, not many studies were undertaken to characterise the performance of solar water-heating systems in South Africa. The current investigation, therefore, focuses on the prediction of seasonal hourly performance trends and the maximum thermal performance of a pressurised system at the fixed optimal slope angle. The system utilises evacuated tube collectors with internal heat pipes with the production of hot service-water for domestic use during all seasons in Pretoria, South Africa. This is accomplished by developing the system's theoretical performance model solved numerically using Engineering Equation Solver (EES).

\section{System configuration}

The system considered to supply domestic hot service-water is shown in Figure 1. In response to the required storage volume for various domestic uses, a number of tanks can be used rather than a single large one. This configuration, moreover, can provide extra storage volume, reduce pressure drops in the collection loop, and set the various operational inlet temperature with regard to the intended applications [15].

This system consists of a solar collector array that absorbs the available solar irradiance and transports the useful heat to the storage unit (Tank 1). The collector system is force-circulated by a pump with a pressure realise facility. The storage unit transfers the heated water for service-water consumption (demand). A secondary pump is used to transport the hot water for the intended application. The water is kept at a minimum temperature by means of an auxiliary heater located inside Tank 1 , which is fed with make-up water from the city supply when the water is consumed. Tank 2 is supplied with makeup water from Tank 1 and can also return water for reheating when a certain temperature tolerance is reached by means of a thermostatic valve. Tank 2 is responsible for supplying the consumption/demand water at a constant temperature, in which scalding is kept in mind. The system parameters can experimentally be measured by the flow meter, pressure transducer and thermocouple, as shown in Figure 1. Parameters can also be measured at state points of importance throughout Tank 1 by the differential temperature controller.

\section{Theoretical analysis}

\subsection{Solar collector model}

The ETHPC in the study consist of a Dewar tube with internal heat pipe configuration to extract the absorbed heat. The Dewar tube consists of two borosilicate glass tubes concentrically layered in a vacuum. This vacuum suppresses conduction and convective heat losses. A cylindrical absorbing surface, also called a selective absorbing coating, is coated on the outside of the inner tube of the vacuum space. This coating has a high absorbing coefficient and a low emissivity value to obtain a high solar energy absorption [16, 17]. Heat pipes consist of a high thermal conductance material that transfers heat to a working fluid embedded inside the heat pipe [7]. The heat pipe consists of an evaporator segment, a condenser segment and an internal working fluid that acts as the liquid- vapour state changing substance located inside the heat pipe [7]. When the evaporator is heated, heat is transferred through the pipe by conduction to the working fluid. The working fluid heats up and evaporates from a liquid state to a vapour state. The heated vapour

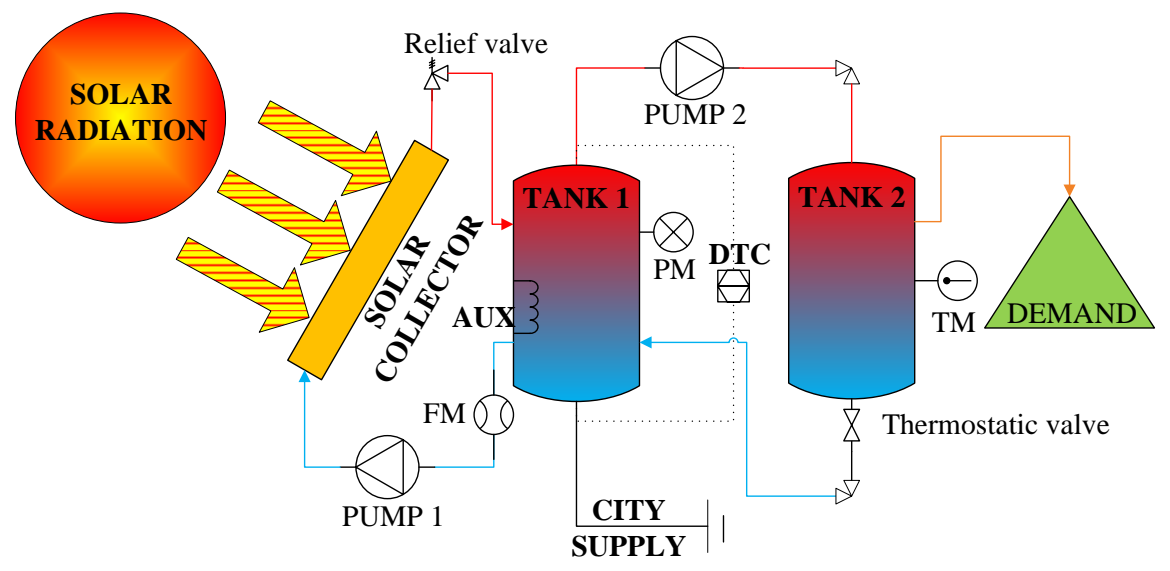

Figure 1: The solar water heating system diagram, where $F M=$ flow meter, $P M=$ pressure transducer, $\mathrm{TM}=$ thermocouple and $\mathrm{DTC}=$ differential temperature controller. 
rises upwards into the pipe to enter the condenser segment [11]. The condenser obtains vapour and, by means of transferring the heat through the heat pipe wall to the manifold cross flowing substance, condenses this vapour back to its liquid state [7]. This condensed liquid returns to the evaporator segment to get heated again, consequently with the cycle repeating itself. The condensed liquid can return to the evaporator segment by gravity [11]. A solar heat pipe collector consists of an array of heat pipes connected to a manifold [18]. The heat pipes, finally, transfers heat to the manifolds' working fluid, as shown in Figure 2.

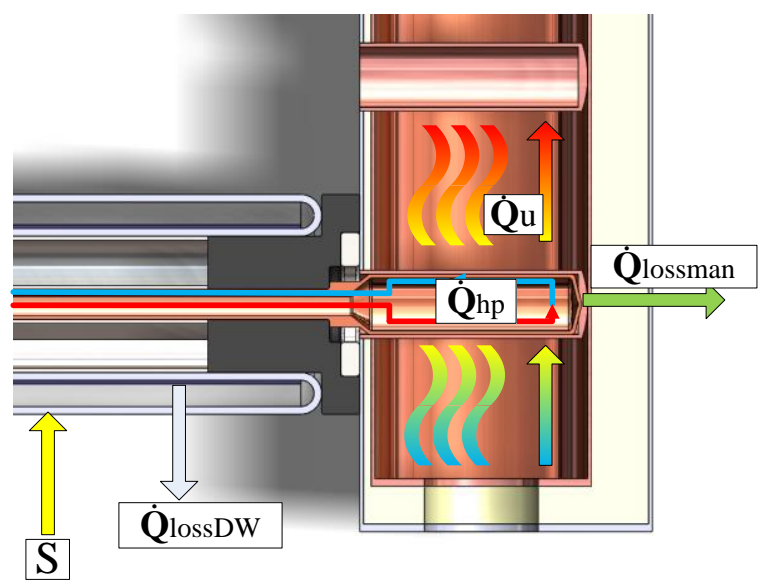

Figure 2: The collector schematic, where $S=$ the incident solar radiation, $\dot{Q}_{\text {loss }_{D W}}=$ overall Dewar tube heat loss, $\dot{Q}_{h p}=$ heat pipe rejected energy to the circulating fluid flowing, $\dot{Q}_{\text {loss }_{\operatorname{man}}}=$ heat loss from the manifold, and $\dot{Q}_{u}=$ useful heat rate.

Using a thermal electrical analogy, as seen in Figure 3, the distribution of incident solar energy into useful energy gain and thermal losses are shown.

A steady state performance of the solar collector can be derived from an energy balance given by Equation 1.

$$
S=\dot{Q}_{\operatorname{loss}_{D w}}+\dot{Q}_{h p}=\dot{Q}_{\operatorname{loss}_{D w}}+\dot{Q}_{u}+\dot{Q}_{\text {loss }_{\text {man }}}
$$

in which $S$ is the product of the incident solar radiation and the transmittance-absorptance product with regard to a chosen sky model; $\dot{Q}_{\text {loss }_{D w}}$ the product of the overall heat loss of the Dewar tube components; $\dot{Q}_{h p}$ the heat pipe rejected energy to the circulating fluid flowing inside the manifold; $\dot{Q}_{\text {loss }}$ the heat loss from the manifold itself; and $\dot{Q}_{u}$ the useful heat transferred out of the collector into the required system. Firstly, heat is transferred by a combination of radiation and wind convection to the ambient environment, from the outer tube. According to Duffie and Beckman [16] the wind convection flow around a single cylinder profile can be expressed using the Adams [16] piecewise relationship given by Equation 2 .

$\mathrm{Nu}=$

$\left\{\begin{array}{cc}0.4+0.54 * R e^{0.52} & \text { for } 0.1<R e<1000 \\ 0.3 * R e^{0.6} & \text { for } 1000<R e<50000\end{array}\right.$

where the Reynolds number is given by Equation 3 .

$$
R e=\frac{\rho * V * L_{C}}{\mu}=\frac{V * L_{C}}{v}
$$

The heat transfer coefficient for natural convection can now be obtained according to Equation 4.

$$
h_{W}=\frac{N u^{*} k_{a i r}}{L_{c}}
$$

If a value less than $5 \mathrm{~W} / \mathrm{m}^{2} \mathrm{~K}$ were found for $h_{w}$, the $h_{w}$ must be taken as $5 \mathrm{~W} / \mathrm{m}^{2} \mathrm{~K}$ [15].

At the outer surface of a singular tube, radiation heat losses to the environment are also present. Radiation heat transfer coefficient to a large infinite area can be calculated by using Equation 5 [19].

$$
h_{r_{g-a}}=\varepsilon_{g} * \sigma *\left(T_{g 2}+T_{a}\right) *\left(T_{g 2}^{2}+T_{a}^{2}\right)
$$

Consequently, the heat transfer coefficient for wind convection and radiation can now be added to obtain a combined heat transfer coefficient for the outer tube surface.

$$
h_{c o m b}=h_{w}+h_{r_{g-a}}
$$

For simplicity, heat transfer resistance between the outer surface and the ambient environment $\left(R_{g-a}\right)$ is expressed as Equation 7 .

$$
R_{g-a}=\frac{1}{A_{D W} * h_{c o m b}}
$$

where heat loss rate can be obtained by Equation 8 .

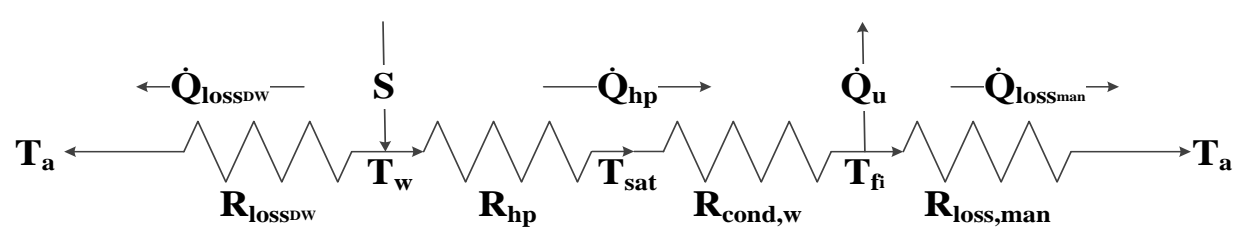

Figure 3: The electrical analogy for a heat pipe solar collector. 


$$
\dot{Q}_{g-a}=\frac{T_{g 2}-T_{a}}{R_{g-a}}
$$

In addition, heat is also transferred to the outer tube by means of conduction. For analysis purposes, the heat transfer rate through the tubes is assumed to be isothermal.

Then, heat transfer by radiation between two concentrically placed cylinders in an evacuated pocket, the heat transfer coefficient $\left(h_{w-g}\right)$, can be determined by Equation 9 [19].

$$
h_{w-g}=\frac{\sigma *\left(T_{w}^{2}+T_{g 1}^{2}\right) *\left(T_{w}+T_{g 1}\right)}{\frac{1}{\varepsilon_{w}}+\frac{A_{w_{w}} *\left(\frac{1}{A_{g}}-1\right)}{\varepsilon_{g}}}
$$

The thermal resistance is stated to be as Equation 10 .

$$
R_{w-g}=\frac{1}{A_{D W} h_{w-g}}
$$

where heat flow can be determined from Equation 11.

$$
\dot{Q}_{w-g}=\frac{T_{w}-T_{g 1}}{R_{w-g}}
$$

The solar irradiance is absorbed by the absorber tube coating. The surface temperature of the absorber coating can be calculated simultaneously with the surface temperature of the outside tube by means of an iteration method.

The total thermal resistance coefficient $\left(R_{\operatorname{loss}_{D W}}\right)$ can be obtained as Equation 12 .

$$
R_{\operatorname{loss}_{D W}}=R_{g-a}+R_{w-g}
$$

where heat rate for the Dewar tube is expressed as Equation 13.

$$
\dot{Q}_{\operatorname{loss}_{D W}}=\left(T_{w}-T_{a}\right) / R_{\operatorname{loss}_{D W}}
$$

Secondly, the heat transfer through the components coupled to the heat pipe and through the heat pipe is determined. The evaporator thermal resistance is represented by $R_{h p}$. It consists of three resistances, namely the circular fin conductance, the pipe conductance and boiling film of the heat pipes internal fluid. The thermal resistance of the evaporator can be written according to Equation 14 [7].

$$
R_{h p}=\frac{\ln \left(\frac{D_{o_{\text {fin }}}}{D_{i_{\text {fin }}}}\right)}{2 * \pi * k_{\text {fin }} * L_{\text {evap }}}+\frac{\ln \left(\frac{D_{o_{\text {ehp }}}}{D_{i_{\text {ehp }}}}\right)}{2 * \pi * k_{h p} * L_{\text {evap }}}+\frac{1}{h_{h p} * A_{\text {evap }}}
$$

where the boiling film heat transfer coefficient for internal cylinder boiling is obtained according to Equation 15 [19].

$$
h_{h p}=0.555\left(\frac{g * \rho_{l} *\left(\rho_{l}-\rho_{v}\right) * k_{l}^{3} *\left(h_{f g}+\frac{3}{8} * c_{l} *\left(T_{w}-T_{s a t}\right)\right)}{\mu_{l} *\left(T_{w}-T_{\text {sat }}\right) * D_{i_{\text {evap }}}}\right)^{\frac{1}{4}}
$$

Similar to the evaporator stage, the condenser stage also has three thermal resistances, namely: the condensing film inside the condenser, the condenser pipe conductance and contact conductance resistance at the dry manifold. The contact resistance can be assumed as negligible. The net amount of thermal resistances at the condenser can be written as Equation 16 [7].

$$
\begin{aligned}
& R_{\text {cond }, w}=\frac{1}{h_{\text {cond }} * A_{\text {cond }}}+\frac{\ln \left(\frac{D_{o_{\text {cond }}}}{D_{i_{\text {cond }}}}\right)}{2 * \pi * k_{\text {cond }} * L_{\text {cond }}}+ \\
& \frac{\ln \left(\frac{D_{o_{c_{m} a}}}{D_{i_{c_{m a} a}}}\right)}{2 * \pi * k_{c_{m a}} * L_{\text {cond }}}
\end{aligned}
$$

where the condensing film heat transfer coefficient for internal cylinder condensing is calculated according to Equation 17 [19].

$$
h_{\text {cond }_{w}}=0.555\left(\frac{g * \rho_{l} *\left(\rho_{l}-\rho_{v}\right) * k_{l}^{3} *\left(h_{f g}+\frac{3}{8} * c_{p_{l}} *\left(T_{w}-T_{s a t}\right)\right)}{\mu_{l} *\left(T_{w}-T_{\text {sat }}\right) * D_{i_{\text {cond }}}}\right)^{\frac{1}{4}}
$$

The heat transfer rate through the heat pipe can be expressed as Equation 18.

$$
\dot{Q}_{h p}=\frac{T_{p}-T_{f i}}{R_{h p}+R_{\text {cond }, w}}
$$

in which $T_{f i}$ is the manifold's sequential fluid temperature.

The manifold thereafter transfers heat from the cross-flowing fluid inside the manifold to the environment as well. Hence, the thermal resistances subjected to heat transfer are conduction of heat through the inner pipe, the insulation, and the outer casing. The conduction for circular profiles can be obtained according to Equation 19 [19].

$$
R_{i}=\frac{\ln \left(\frac{D_{o_{i}}}{D_{i_{i}}}\right)}{2 * \pi * k_{i} * L_{i}}
$$

where $i$ can be replaced with the section indicators, for example, insulation thermal resistance is presented as $R_{\text {ins }}$.

At the surface of the outer casing, heat is distributed to the environment by the combined thermal 
resistance of wind convection and radiation. Assuming constant cross flow of the wind over the collector, it is necessary to calculate flow over the manifold in the same direction. Therefore, according to Duffie and Beckman [16], flow over a flat surface can be assumed, and as such, determine the wind heat transfer coefficient using Mitchell's equation [16] in Equation 20.

$$
h_{w_{\text {man }}}=\frac{8.6 * V^{0.6}}{L^{0.4}}
$$

where $V$ and $L$ represents the wind speed and pitch length of the manifold, respectively. The combined wind, radiation coefficient and thermal resistances at the manifold can be similarly obtained as formerly determined. The thermal resistance of the total manifolds' thermal resistance can be gained as Equation 21.

$$
R_{\text {man }}=R_{I T}+R_{I N S}+R_{O T}+R_{\text {comb }_{W-r a d}}
$$

Such that the manifold heat loss can be expressed as Equation 22.

$$
\dot{Q}_{\text {loss }_{\text {man }}}=\frac{T_{f i}-T_{a}}{R_{\operatorname{man}}}
$$

Finally, with the thermal characteristics known, the thermal performance of a solar collector can be determined. The energy balances can be rewritten and manipulated as in the series of Equations 23, 24, 25 and 26.

$$
\begin{aligned}
& \dot{s} * A_{r}=\frac{T_{w}-T_{a}}{R_{\text {loss }_{D W}}}+\dot{Q}_{u}+\frac{T_{f i}-T_{a}}{R_{\text {loss }_{\text {man }}}} \\
& \dot{s} * A_{r}=\frac{T_{w}-T_{a}}{R_{\text {loss }_{D W}}}+\frac{T_{w}-T_{s a t}}{R_{h p}} \\
& \dot{Q}_{u}=\frac{T_{\text {sat }}-T_{f i}}{R_{\text {cond }, w}}-\frac{T_{f i}-T_{a}}{R_{\text {lossman }_{\text {man }}}} \\
& \dot{Q}_{h p}=\frac{T_{w}-T_{f i}}{R_{h p}+R_{\text {cond }, w}}=\dot{Q}_{u}+\frac{T_{f i}-T_{a}}{R_{\text {loss }_{\text {man }}}}
\end{aligned}
$$

From these, a single simplified expression is developed for the useful energy obtained from the solar collector in terms of all collector components in which the absorbed solar radiation, manifold fluid temperature, and ambient temperature are known and expressed by Equation 27.

$$
\dot{Q} u=\frac{\dot{s} * A_{r}}{1+R_{h r}+R_{c r}}-
$$

$$
\frac{T_{f}-T_{a}}{1+R_{h r}+R_{c r}}\left(\frac{1}{R_{\text {loss } D W}}+\frac{1}{R_{\text {lossman }}}\left(1+R_{h r}+R_{c r}\right)\right)
$$

The ratios in Equations 28 and 29 are used in the numerical manipulations:

$$
R_{h r}=\frac{R_{h p}}{R_{\text {loss }_{D W}}}
$$

and

$$
R_{c r}=\frac{R_{\text {cond }, w}}{R_{\text {loss } D W}}
$$

The collector efficiency factor can be obtained by Equation 30.

$$
F^{\prime}=\frac{1}{1+R_{h r}+R_{c r}}=\frac{\frac{1}{R_{\text {loss } d w}}}{\frac{1}{R_{\text {loss } d w}}+\frac{1}{R_{h p}}+\frac{1}{R_{\text {cond }, w}}}
$$

And the overall heat loss coefficient of the collector $\left(\boldsymbol{U}_{\boldsymbol{l}_{o}}\right)$ can be obtained by Equation 31.

$$
U_{l_{o}}=\frac{1}{R_{\operatorname{rad}^{*} A_{r}}}+\frac{1}{R_{\operatorname{man}} * A_{r} * F^{\prime}}
$$

The heat removal factor of the collector can be found by Equation 32 [16].

$$
F_{R}=\dot{m} * \frac{C_{p}}{A_{r} * U_{l}} *\left(1-E X P\left(-\frac{U_{l} * A_{r} * F^{\prime}}{\dot{m} * C_{p}}\right)\right.
$$

The actual useful energy, in terms of the heat removal rate, can now be rewritten as Equation 33.

$$
\dot{\mathrm{Q}}_{\mathrm{u}}=F_{R} * A_{r} *\left(\dot{s}-U_{l} *\left(T_{f}-T_{a}\right)\right)
$$

To obtain the temperature leaving the manifold, Equation 34's usable heat expression is used [19].

$$
\dot{\mathrm{Q}}_{\mathrm{u}}=\dot{m} * C_{p} *\left(T_{f o}-T_{f i}\right)
$$

Lastly, the instantaneous efficiency can be obtained as the ratio of actual useful heat to the absorbed solar radiation, as in Equation 35.

$$
\eta=\frac{\dot{Q}_{u}}{\dot{s} * A_{r}}
$$

It should be noted that $F_{R}$ and $U_{l_{o}}$ are independent of the solar radiation. The efficiency is obtained from the amount of radiation absorbed at the receiver wall and not from the ambient. 


\subsection{Storage model}

Assuming a fully mixed (un-stratified) storage scenario, the liquid storage unit capacitance $\left(\dot{Q}_{s t}\right)$ at uniform temperature, operating over a finite temperature difference $\left(\Delta T_{S}\right)$, is expressed as Equation 36 [16].

$$
\dot{Q}_{s t}=(M * C p)_{s} *\left(\Delta T_{s}\right)
$$

in which $M$ is the mass of the storage volume capacity.

The rate of energy loss from the tank can be expressed according to Equation 37 [19].

$$
\dot{Q}_{t l}=(U A)_{s} *\left(T_{s}-T_{e n v}\right)
$$

in which $(U A)_{s}$ is the storage tank's overall heat transfer coefficient-area product and $T_{e n v}$ is the storage tank's surroundings ambient temperature.

Generally, with some mathematical manipulation, the fully mixed storage tank temperature to be supplied to the next collector loop $\left(T_{s-n}\right)$ can be obtained by Equation 38 [16].

$T_{s-n}=T_{s}+\frac{\Delta t}{(M * C p)_{s}} *\left(\dot{Q}_{u}-\sum \dot{Q}_{l}-(U A)_{s} *\left(T_{s}-T_{e n v}\right)\right)$

This equation assumes constant heat losses for a set time period, preferably on an hourly basis.

Considering the application load, the crucial parameter to be considered in the intended application of water heating is the water consumption/demand $(D E M)$ over a certain time period. This can be determined as Equation 39 [16].

$$
D E M=\dot{m} * C p *\left(T_{s}-T_{m u}\right)=V * \rho * C p * \frac{\left(T_{s}-T_{m u}\right)}{t}
$$

in which $\dot{m}$ is the mass consumption rate for a set time period, $V$ is the volumetric consumption capacity, $T_{s}$ the water distribution temperature and $T_{m u}$ the public main water temperature.

\subsection{The simple system model}

Consequently, a simple system model expresses the summation of all physical components' heat load and losses. The model can be expressed as Equation $40[15,16]$.

$$
\dot{Q}_{s}=\sum \dot{Q}_{u}-\sum \dot{Q}_{l}-\sum \dot{Q}_{t l}
$$

The total heat collected $\left(\sum \dot{Q}_{u}\right)$ is the summation of the collected useful solar energy and the auxiliary heat obtained from an auxiliary source. The total rate of heat removed from the intended load application $\left(\sum \dot{Q}_{l}\right)$ is the summation of the water heat de- mand and miscellaneous components such as piping, heat exchanger and other connectivity devices [15]. Lastly, the summation of all losses from the tanks themselves is expressed as $\sum \dot{Q}_{t l}$.

\section{Component specifications}

The ETHPC consists of a borosilicate glass Dewar tube with copper internal heat pipe, in which water is used as the internal fluid. The circular aluminum fin is $1 \mathrm{~mm}$ thick and $1675 \mathrm{~mm}$ long. The dry type pressurised manifold has a $1 \mathrm{~mm}$ thick separation wall and is operated at a pressure of $400 \mathrm{kPa}$. The manifold consists of a copper internal shell, polyurethane foam insulation and a stainless steel outer layer. The manifolds' internal fluid is also water. Both storage tanks are of similar size with a volume capacity of 1501 each with a U-Value of $0.16 \mathrm{~W} / \mathrm{m}^{2} \mathrm{~K}$. Table 1 shows design specifications for the collector. These specifications are formulated from measurement and datasheets from local distributors in the area $[20,21]$. The collector consists of a 20-tube ETHPC with internal heat pipes that have a net absorption area of $2.6125 \mathrm{~m}^{2}$. The manifold circulates water at a mass flow rate of $0.03 \mathrm{~kg} / \mathrm{s}$.

Table 1: Solar collector specifications.

\begin{tabular}{lccc}
\hline Component & Dimension & Value & Unit \\
\hline Glass tube & $\mathrm{D}_{\mathrm{O}_{\mathrm{O}}}$ & 58 & $\mathrm{~mm}$ \\
& $\mathrm{D}_{\mathrm{o}_{\mathrm{i}}}$ & 46.2 & $\mathrm{~mm}$ \\
& $L$ & 1800 & $\mathrm{~mm}$ \\
& $\Delta \mathrm{x}$ & 2.2 & $\mathrm{~mm}$ \\
& $\varepsilon_{\mathrm{g}}$ & 90 & $\%$ \\
\hline Absorber tube & $\varepsilon_{\mathrm{r}}$ & 6 & $\%$ \\
coating & $\alpha$ & 94 & $\%$ \\
\hline Copper evap- & $\mathrm{D}_{\mathrm{o}}$ & 8 & $\mathrm{~mm}$ \\
orator & $\Delta \mathrm{x}$ & 1.2 & $\mathrm{~mm}$ \\
\hline Copper & $\mathrm{D}_{\mathrm{o}}$ & 14 & $\mathrm{~mm}$ \\
condenser & $\mathrm{L}$ & 57.5 & $\mathrm{~mm}$ \\
& $\Delta \mathrm{x}$ & 1.2 & $\mathrm{~mm}$ \\
\hline Manifold & $\mathrm{D}_{\mathrm{i}}$ & 60 & $\mathrm{~mm}$ \\
& $\Delta \mathrm{x}_{\mathrm{IT}}$ & 2.4 & $\mathrm{~mm}$ \\
& $\Delta \mathrm{x}_{\mathrm{INS}}$ & 100 & $\mathrm{~mm}$ \\
& $\Delta \mathrm{x}_{\mathrm{OT}}$ & 1.4 & $\mathrm{~mm}$ \\
\hline
\end{tabular}

\section{Environmental conditions}

The hourly performance trend of a solar water-heating system was studied at various collector slope an- 
gles between 06:00 and 19:00. At different slope angles, the system's performance was investigated for 21 March (autumn), 21 June (winter), 21 September (spring) and 21 December (summer). The slope angles investigated were $25^{\circ}, 30^{\circ}, 35^{\circ}$ and $40^{\circ}$. A theoretical meteorological year was created, based on data obtained from the South African Weather Service [22, 23]. The maximum wind velocity was taken as $4.7 \mathrm{~m} / \mathrm{s}$ for March, $7.3 \mathrm{~m} / \mathrm{s}$ for June, $8.5 \mathrm{~m} / \mathrm{s}$ for September and $5.1 \mathrm{~m} / \mathrm{s}$ for December. Solar irradiance and the hourly ambient temperature are illustrated in Figure 4.

The hourly repetitive water demand, referred to as the consumption profiles for a typical South African townhouse is shown in Figure 5.

The South African spring and autumn climates are similar to summer, therefore, the water consumption profile for summer is applicable to spring and autumn. Water is supplied to users at $60{ }^{\circ} \mathrm{C}$ to eliminate bacterial growth, as recommended by Duffie and Beckman [16].

\section{System simulation}

For the purpose of investigating the performance of the system as a whole and all the models (TMY model, solar collector, storage, demand and the simple system model) were programmed and implemented in a software code, EES. The program is made up of four conventional programs. The first program consists of the database and compiles the input parameters from the TMY and the absorbed radiation. The results of each modelling sequence are stored at hourly intervals. The capability of the database is extended to analysing and comparing the data through which the capability to compare the system components performance trends are generated. The second program is the iterative program, which models the collector. The model analyses the hourly thermal behaviour of each solar receiver systematically. According to the energy balance earlier presented, the Dewar tube, heat pipe (evaporator and condenser) and manifold are analysed. The program is further extended to anal-
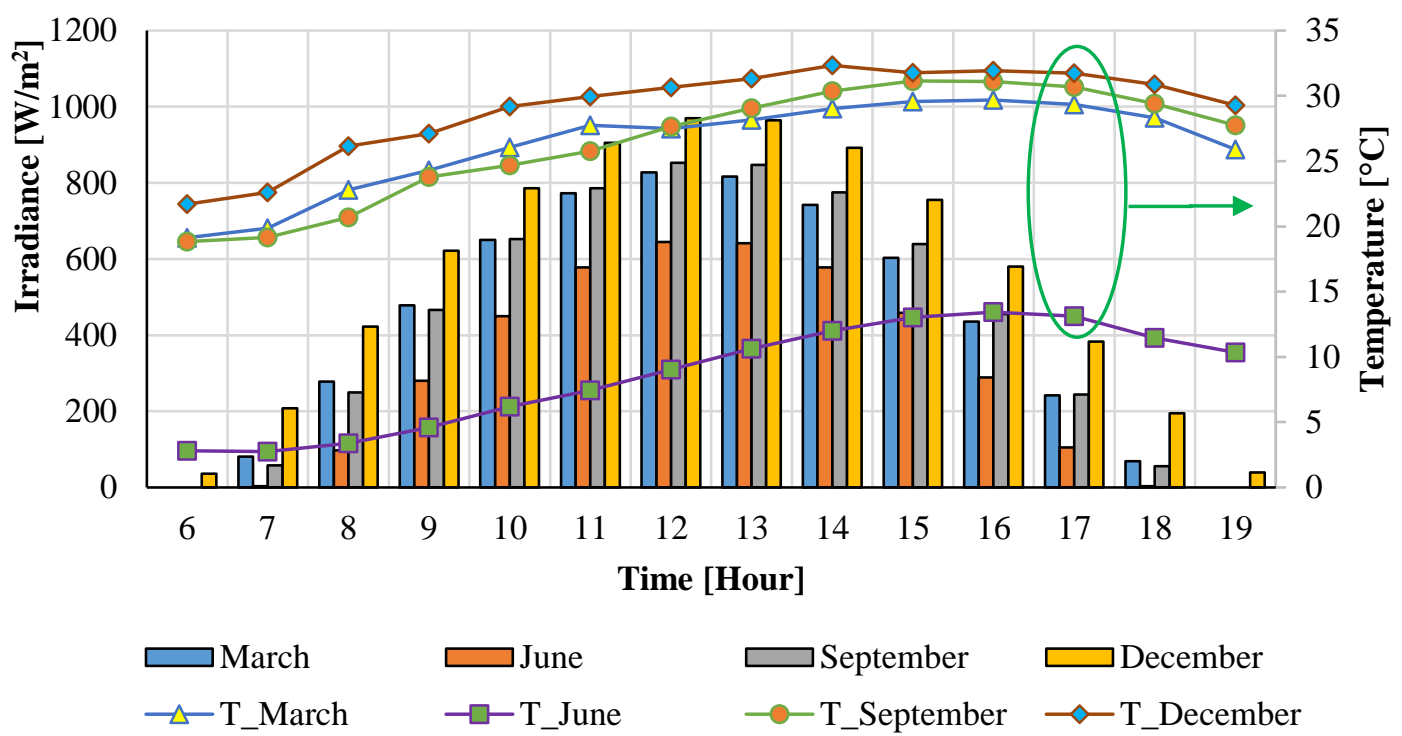

Figure 4: The solar irradiance and ambient temperature.

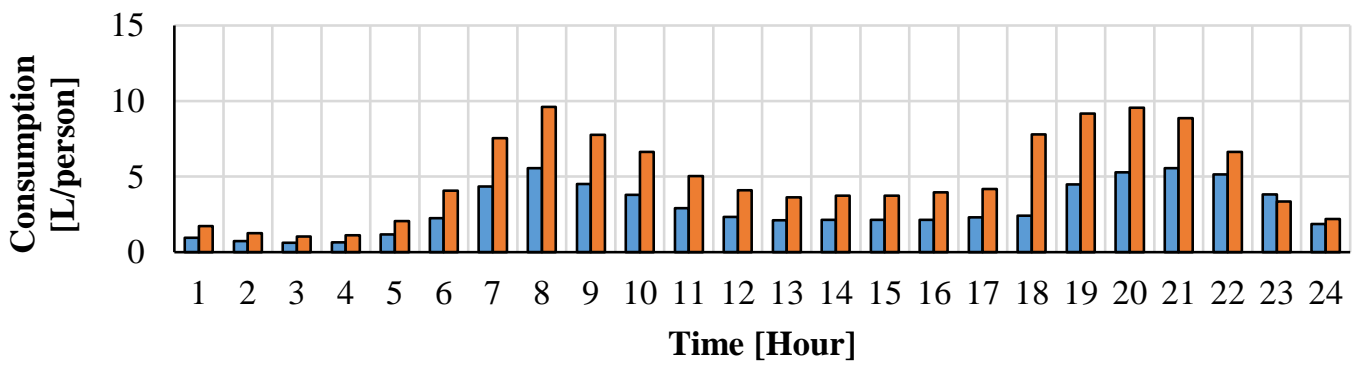

$\square$ Summer $\square$ Winter

Figure 5: Typical family average hourly water consumption for the winter and summer seasons in South Africa [24]. 
yse the thermodynamic performance of the complete solar collector. Important quantities are obtained, such as the useful heat gain, the outlet manifold temperature, the heat removal rate, the collector efficiency factor and the collector efficiency, all from the numerical simulation. The third program is the compilation of the storage and demand/consumption load. This program was created with the intent of obtaining the applications loads. Subsequently, the loads are compiled into the simple model and the next temperature input to the collector at the next interval sequence is determined. Therefore, the application load effects with respect to the solar capability can be investigated. The last program, the macro, controls these former programs and guides the hourly interval investigation of the system components. This program is also responsible for exporting and importing the database data to and from the EES programs. The macro can be visualised in Figure 6.

\section{Results and discussion}

\subsection{Model validation}

The model results for the evaluation of the thermal characteristics and performance of the solar collector were compared with results obtained from an experimental study by Jafarkazemi et al. [9]. Experimental data from this study was collected in the solar energy laboratory building at the Islamic Azad University, South Tehran. The tests are based on the ISO 9806-1 Standard. The sensors were calibrated for both the temperature (PT-100 sensors) and the mass flow rate (Max $0.04 \mathrm{~kg} / \mathrm{s})$. The developed EES program is solved for a four tube collector tilted at $45^{\circ}$ slope angle with the same parameters as used by Jafarkazemi et al. [9]. The obtained outlet temperatures are plotted against time, as shown in Figure 7. In this figure, the experimental values of the outlet temperature ( $\left.T_{\text {experimental }}\right)$ and theoretical values ( $\left.T_{\text {theoretical }}\right)$ are plotted against the model values obtained in this study $\left(T_{\text {model }}\right)$.

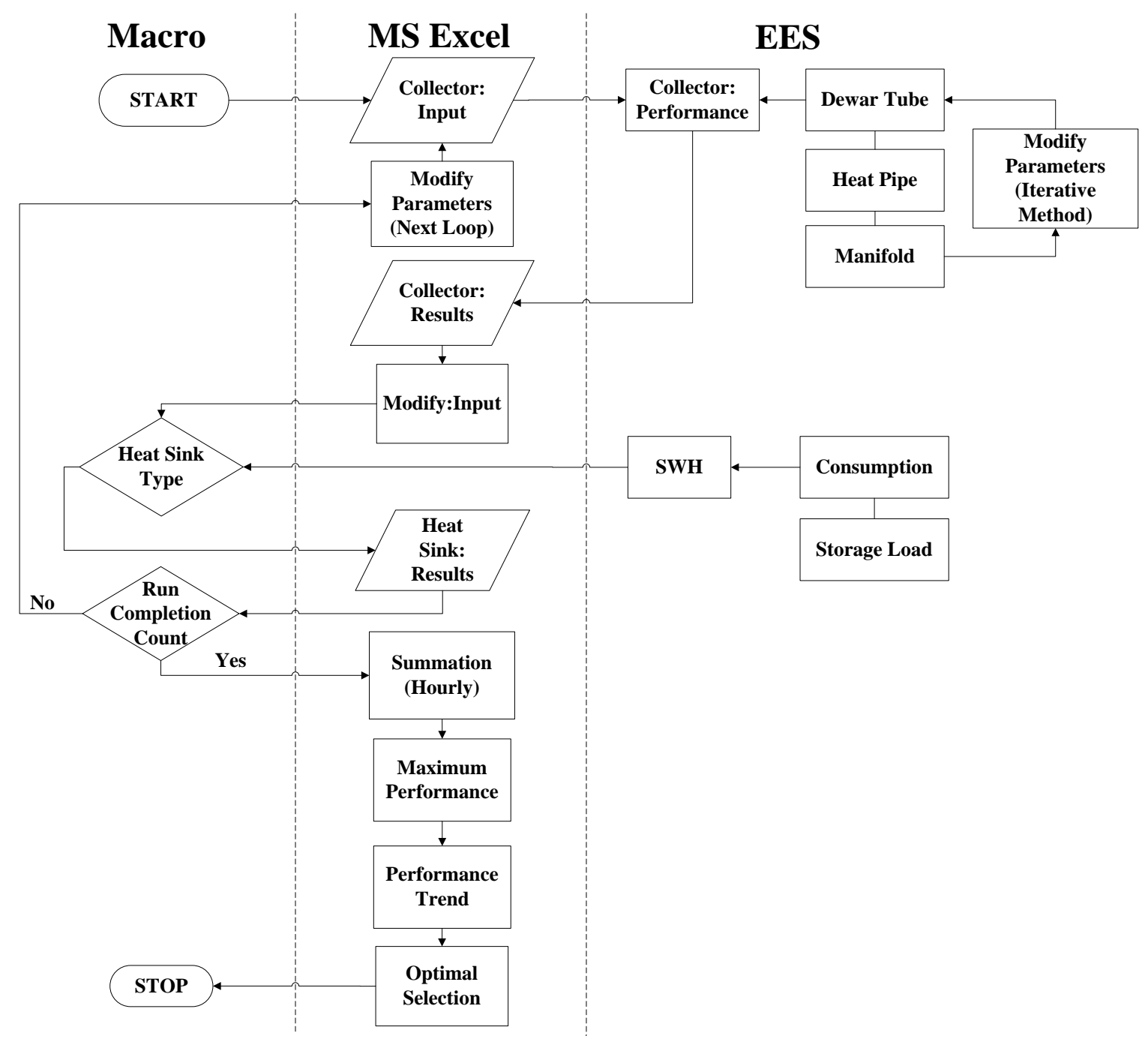

Figure 6: Macro operation layout. 


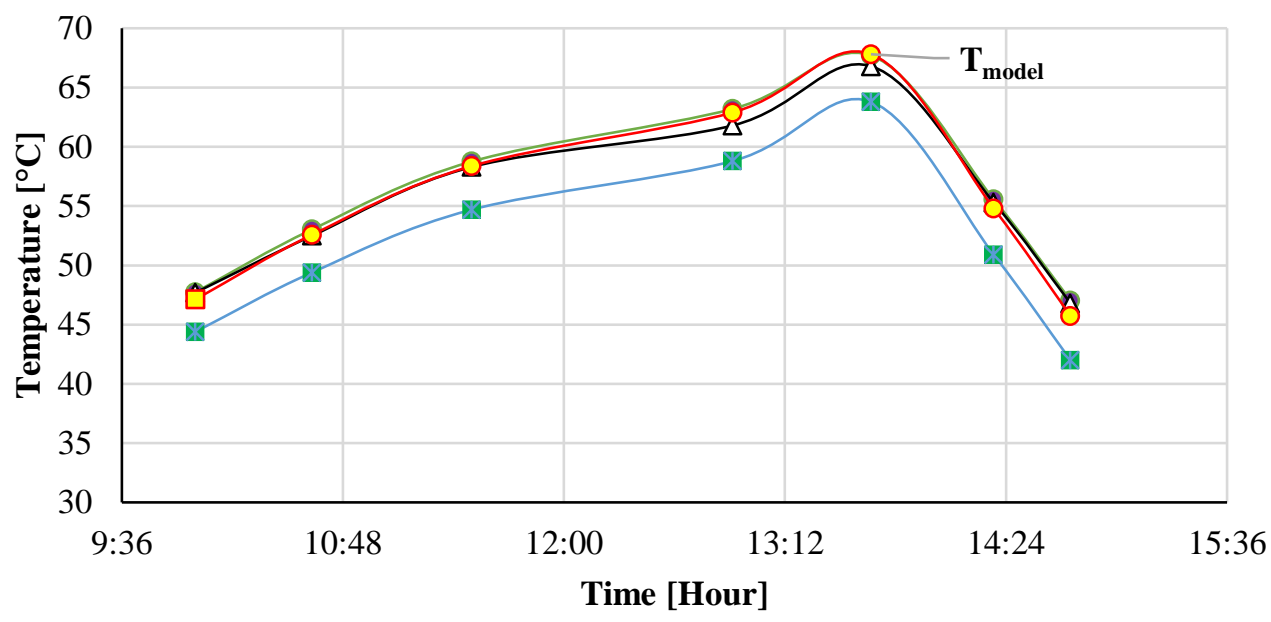

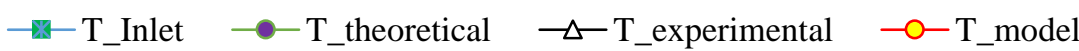

Figure 7: Comparison between the experimental, theoretical and the model results.

Based on the results summarised in Figure 7, the model accurately predicts the performance of a $\mathrm{SWH}$ system. The model predicts the outlet temperature within $\pm 3 \%$ of the experimental values.

\subsection{System performance}

The following results were accomplished by taking into consideration the hourly domestic water consumption load given in Figure 5. The absorbed rad- iation was determined using an isotropic sky model with the assumption of a clear sky and no shading influences. The collector was taken to be mounted due North, as it is located in the Southern hemisphere. The hourly plotted trend of useful heat rate $\left(\dot{Q}_{u}\right)$, outlet temperatures $\left(T_{o}\right)$ and collector efficiency $(\eta)$ for different months, representing different seasons, is shown in Figure 8 (below, continuing on next two pages).
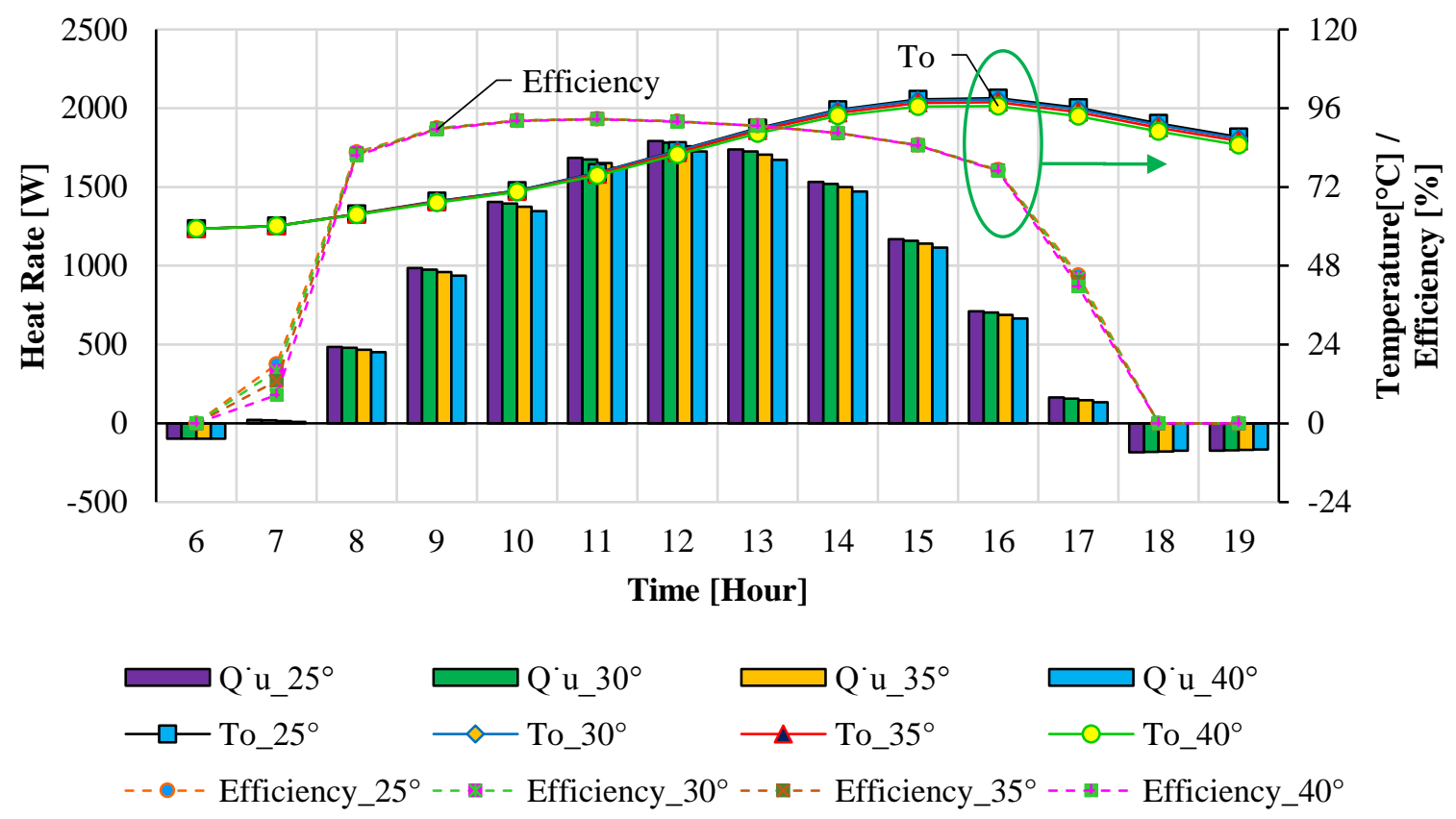

$\operatorname{March}(\mathbf{A})$ 

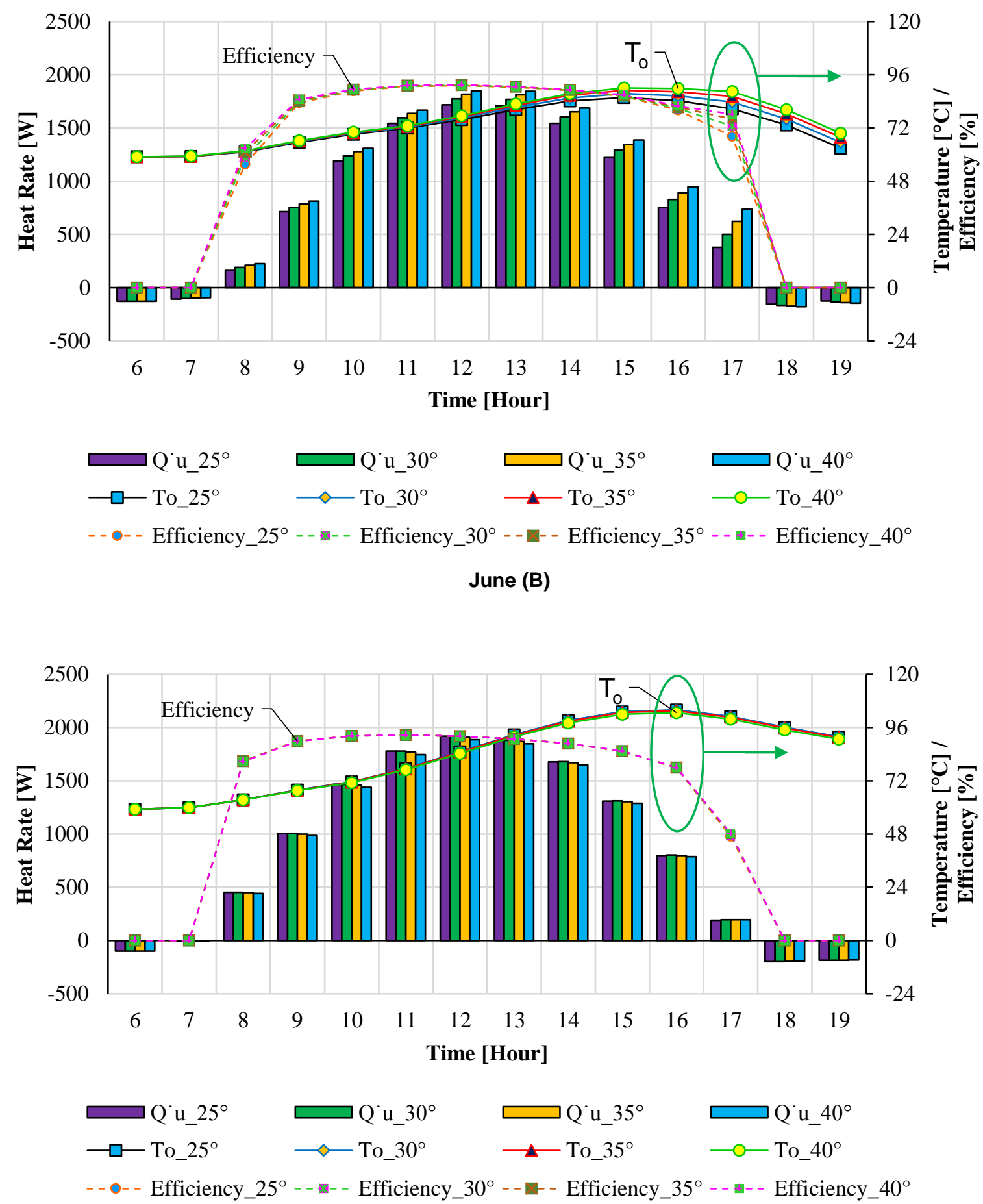

September (C) 

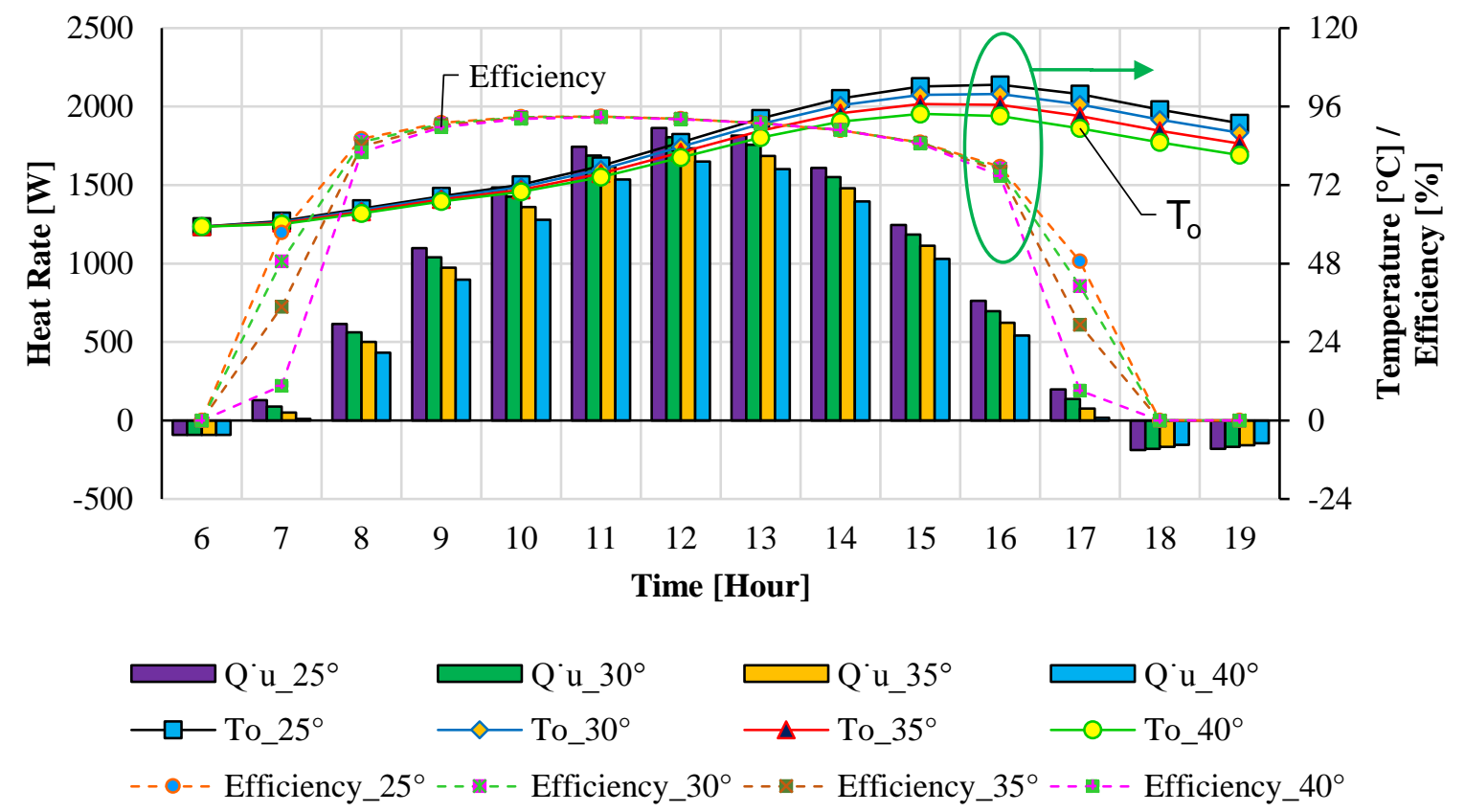

December (D)

Figure 8: Collector slope performance trends for March, June, September and December.

From these figures, the trends are similar at different tilt angles during the seasons, but vary in the potential amount absorbed. This can be traced back to the solar angle relations in the sky model, in which the two-degree movement of the sun in its celestial orbit plays a crucial role. On 21 March (autumn) and 21 September (spring), the irradiance incident angle on the surface of the collector slopes are close to equilibrium and geometric factors are equal. This results in the amount of absorbed heat to be similar, respective to the season. In addition, given that the absorbed amount of heat is similar for all the slope angles in the specific season, the temperature and efficiency should rise, peak and fall accordingly with minor differences. An observation of the yearly solstices, 21 December and 21 June, shows that the amount of heat increases and decreases stepwise in relation to the slope angle. The incidence angles on the surface of the collector vary with the slopes angles, and as such are related to the largest and smallest angles to use in these seasons. Considering the dependence of incident angle on the heat absorption, as previously discussed, an inference can be made about the relationship between the two variables. For a system producing service-water, in summer, the slope of $40^{\circ}$ is found to produce the least amount of useful heat and outlet temperature, whereas a slope of $25^{\circ}$ produces the most. However, the precise opposite is found in winter, when $40^{\circ}$ slope produces the most. The same inverse seasonal relationships are found for slope angles of $35^{\circ}$ and $30^{\circ}$. Nonetheless, this provide an insight into optimal performance prediction during the year. The capacitance is significantly affected by the service-water demand in such a way that the capacitance is insufficient for temperature rises in the early-morning and afternoon hours. These are the hours of highest demand, resulting in the inability of the system to comply with the required output. In periods of low demand, the system temperature increases despite the steady decrease of absorbed radiation. This is due to the tank capacitance being higher than the demand requirement in these time periods. The collectors' capacity to absorb the incoming heat in morning and afternoon hours is limited to the available irradiation. As such, when little to no irradiance is available, the collector emits higher internal manifold working fluid heat to the colder environment. Similarly, the consumption rate at these hours assists in preventing useful heat gain to increase. These factors that limit heat gain cause the thermal efficiency to be zero in these periods. However, in periods of abundant irradiance, the efficiency quickly increases, reaches a peak and decreases due to its dependency on the temperature differences of the manifold's inlet and outlet. Intrinsically, the collectors' temperatures are dependent on the tank temperature that supply the collectors' manifold. The tank temperature that supplies the manifold is confined to the 
simple system model expression. As such, as the useful heat surpasses the consumption loads and heat losses from the components, the inlet temperature to the next collector loop increases. If the consumption loads overwhelm the useful heat, the tank temperature will decrease, thereby decreasing the next collector loop inlet temperature. When irradiation is abundant and demand is low, the inlet and outlet temperatures of the collector will, therefore, increase. When the inlet temperature of the collector increases over time, however, the temperature difference of the collector will decrease. The tank temperatures and storage quantities can be visualised as in Figure 9. Examining the optimum output parameters for the different slope angles, as shown in Table 2, an inference can be made regarding the optimal slope angle.

The maximum temperature obtained is close to scalding and, therefore, utilising only one tank can be seen as dangerous. A multi-tank system can control the required temperature to be supplied to the occupants, making it the favourable choice. The system is pressurised at $400 \mathrm{kPa}$ and the stagnation temperature is $143.65^{\circ} \mathrm{C}$, therefore the working fluid is also still in a liquid state at the higher obtainable temperatures. The efficiency in this study is defined as the ratio of useful heat to the absorbed irradiance. This will result in higher efficiency values compared with the values abtained according to the definition of Hayek et al. [14]. These authors define efficiency in terms of the available irradiance. The manufacturer's efficiency of $80-85 \%$ is estimated according to this definition. It is, nonetheless, believed that the acquired results are principally expected.

In decision, the $30^{\circ}$ slope is identified as the optimal angle with regard to the various seasons and also fluctuates minimally between the solstices. This angle results in very similar values in March, compared to the $25^{\circ}$ angle and yield the highest values in September. It is likely that the $30^{\circ}$ slope is also the optimal choice in Pretoria.

\section{Conclusions}

A numerical model was developed and implemented in Engineering Equation Solver to investigate the performance of a SWH system. The developed model predicted the performance of a practical system within $\pm 3 \%$ of the experimental values. This model can, therefore, be used to provide reliable results of a solar water heating system at any given operating conditions. Results from the analysis showed similar trends for the performance at different tilt angles. In summer, the $40^{\circ}$ slope pro-

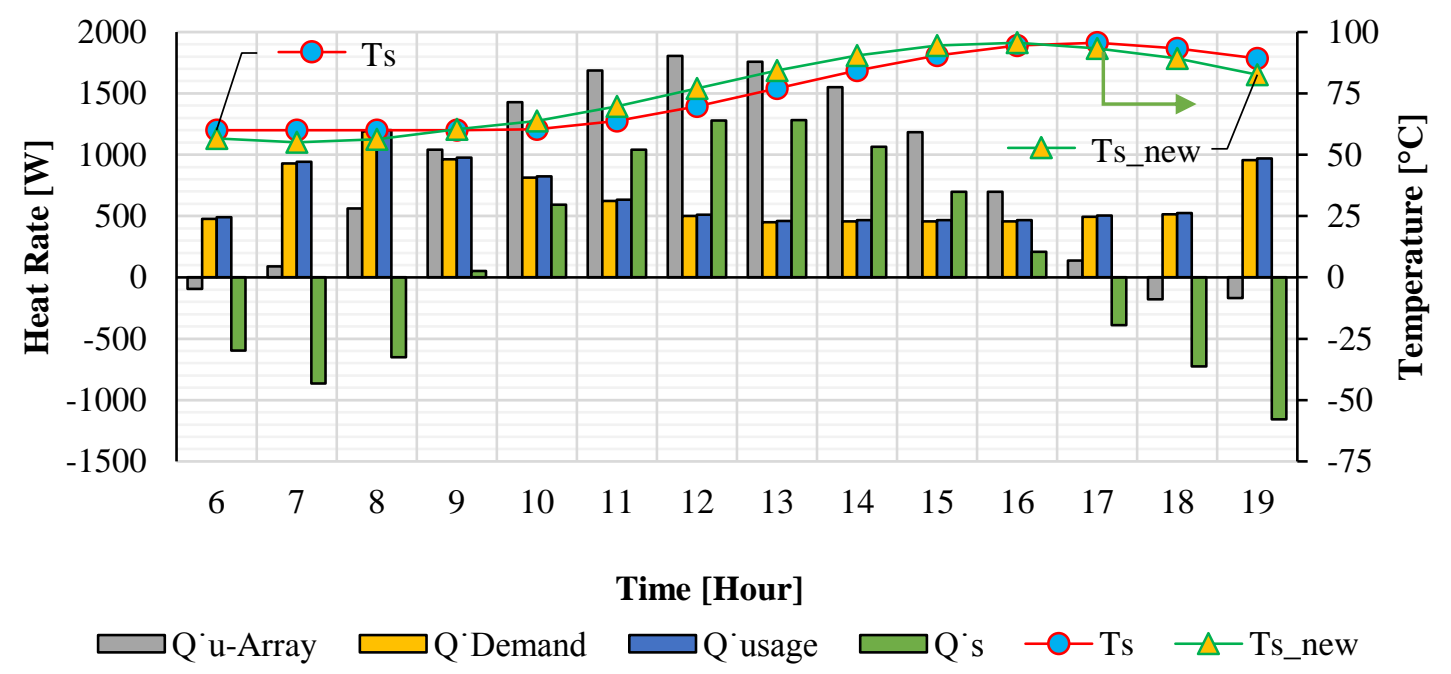

Figure 9: Storage performance trend in solar water-heating application (December).

Table 2: Slope angle maximum performance values.

\begin{tabular}{ccccc}
\hline & March & June & September & December \\
\hline$\dot{\boldsymbol{Q}}_{\boldsymbol{u}}[\boldsymbol{W}]$ & 1791.10 & 1849.25 & 1919.85 & 1862.83 \\
$\boldsymbol{T}_{\boldsymbol{o}}\left[^{\circ} \boldsymbol{C}\right]$ & 99.10 & 90.06 & 103.98 & 102.68 \\
Efficiency [\%] & 92.74 & 91.43 & 92.70 & 92.95 \\
Slope angle $\left(^{\circ}\right)$ & $25^{\circ}$ & $40^{\circ}$ & $30^{\circ}$ & $25^{\circ}$ \\
\hline
\end{tabular}


duced the least amount of useful heat and outlet temperature, whereas the $25^{\circ}$ slope produced the most. In winter, the opposite was observed, and the $40^{\circ}$ slope produced the greater amount. The same inverse seasonal relationships are found for slope angles of $35^{\circ}$ and $30^{\circ}$. In autumn and spring, the collector produced similar results during the slope angles with small differences. The optimal seasonal slope angle for a SWH system was identified as $30^{\circ}$. Lastly, a 20-receiver tube collector system operated maximally in September, reaching an outlet temperature of $103.98{ }^{\circ} \mathrm{C}$ and yielding a useful heat rate of $1919.85 \mathrm{~W}$.

\section{Acknowledgements}

The support received from the Tshwane University of Technology and the University of the Witwatersrand is acknowledged. The support received from the National Research Foundation is also acknowledged. Special thanks to the South African Weather Service for providing data used in this investigation.

\section{References}

1. Eskom. 2015. COP17 Fact sheet : Solar water heating rebate program [Online]. Available: http:// www.eskom.co.za/AboutElectricity/FactsFigures/ Documents/The Solar_Water_Heating_SWH Programme.pdf [Accessed 2015/03/09 2015].

2. REN21 2014. Renewable energy 2014 global status report. Paris: REN21 Secretariat.

3. Centre for Renewable and Sustainable Energy Studies and AEE- INTEC. 2014. The South African solar thermal technology road map [Online]. Available: www.solarthermalworld.org/sites/gstec/ modules/ pubdlcnt/pubdlcnt.php?file $=$ http://www. solarthermalworld.org/sites/gstec/files/story/2014 12-05/solar-thermal-road-map-working-document3-nov-2014.pdf\&nid =63774 [Accessed 2015/03/09].

4. Allouhi, A., Jamil, A., Kousksou, T., Mourad, Y. and Zeraloui, Y. 2015. Solar domestic water heating system in Morocco: An energy analysis. Energy Conversion and Management, 92, 105-113.

5. Hazami, M., Kooli, S., Naili, N. and Farhat, A. 2013. Long-term performances prediction of an evacuated tube solar water heating system used for single-family households under typical NorthAfrican climate (Tunisia) Solar Energy, 94: 283298.

6. Mazarron, F. R., Porras-Prieto, C. J., Garcia, J. L. and Benavente, R. M. 2016. Feasibility of active solar water heating systems with evacuated tube collector at different operational temperatures. Energy Conversion and Management, 113: 16-26.

7. Jafarkazemi, F. and Abdi, H. 2012. Evacuated tube solar heat pipe collector model and associated tests. Journal of Renewable and Sustainable Energy, 4: 1-13.
8. International Organization for Standardization 1994. ISO 9806-1:1994 Test methods for solar collectors - Part 1: Thermal performance of glazed liquid heating collectors including pressure drop.

9. Jafarkazemi, F., Ahmadifard, K. and Abdi, H. 2016. Energy and exergy of heat pipe evacuated tube solar collectors Thermal Science, 20: 327335.

10. Hlaing, S. and Soe, M. M. 2012. Design calculation and heat transfer analysis of heat pipe evacuated tube solar collector for water heating. International Journal of Science, Engineering and Technology Research (IJSETR), 1, 1-5.

11. Azad, E. 2008. Theoretical and experimental investigation of heat pipe solar collector. Experimental Thermal and Fluid Science, 32: 16661672.

12. Briel, A. Z. A. and Bunt, E. A. 1994. Optimization of flat plate solar collector angles at a latitude just outside the tropics. N\&O Joernaal, 10: 58-60.

13. Asowata, O., Swart, J. and Pienaar, C. 2012. Optimum tilt angles for photovoltaic panels during winter months in the Vaal triangle, South Africa. Smart Grid and Renewable Energy, 3, 119 - 125.

14. Hayek, M., Assaf, J. and Lteif, W. 2011. Experimental investigation of the performance of evacuated tube solar collectors under eastern mediterranean climatic conditions. Energy Procedia, 6: 618-626.

15. Kalogirou, S. A. 2014. Solar energy engineering processes and systems Oxford, United Kingdom, Elsevier.

16. Duffie, J. A. and Beckman, W. A. 2013. Solar engineering of thermal processes, Canada, John Wiley \& Sons.

17. ITS Solar. 2015. How does an evacuated tube heat pipes collector work? [Online]. Available: http://www.itssolar.co.za/download.php?file =evac/ ITS\%20-\%20How\%20does\%20Evacuated\%20\% 20Tubes\%20work.pdf [Accessed 2015/08/11].

18. Ng, K. C., Yap, C. and Khor, T. H. 1999. Outdoor testing of evacuated tube heat-pipe solar collectors. Institution of Mechanical Engineers, 214 2330.

19. Cengel, Y. A. and Ghajar, A. J. 2011. Heat and mass transfer: Fundamentals and applications, New York, Mc Graw Hill.

20. ITS Solar. 2015. Evacuated tube specifications [Online]. ITS Solar. Available: http://www.itssolar.co.za/download.php?file = evac/ITS-10-15-20Evacuated-Tube-Specifcations.pdf [Accessed 2015/07/21].

21. Solarray. 2015. High pressure solar water heater catalogue [Online]. Solarray. Available: http://solarpowergeyser.co.za/high-pressure-solar-waterheater-150-1/ [Accessed 2015/07/22].

22. South African Weather Service 2015. Global, beam and diffuse irradiance of Pretoria, South Africa (January 1957-December 1987)

23. South African Weather Service 2015. Meteorological data of Pretoria UNISA, South Africa (January 2009-December 2014). 
24. Meyer, J. P. and Tshimankinda, M. 1996. Domestic hot water consumption in South African townhouses. Energy Conversion and Management, 39, 679-684. 